\title{
Heel Pressure Sore: Surgical treatment with the Cone Flap
}

\author{
Calderon Wilfredo, ${ }^{1 *}$ Camacho Juan Pablo, ${ }^{2}$ Obaid Miguel, ${ }^{3}$ Subiabre Rodrigo, ${ }^{3}$ Lombardi Juan José, ${ }^{2}$ Iribarren $0 s-$ \\ valdo $^{2}$ \\ ${ }^{1}$ Professor and Chief of Service, Chile \\ ${ }^{2}$ Plastic surgeons, Chile
}

${ }^{3}$ General surgeons, Chile

\begin{abstract}
Introduction: The patients with paraplegia may present pressure sores in the heel because is an area offriction and shearing with a thin and insensible tigth skin. The treat ment include many flaps but ussually they are of difficult procedure. The Cone flap, described in PRS, is a good, reliable aneasy flap for treatment of the pressure sore in the heel.
\end{abstract}

Objetive: Show the casuistic of the Cone flap for repair of the pressure sore of the heel in paraplegic patients.

Material and Method: Since 2016 through 2019 we operated on ten paraplegics patients with pressure sore in the heel with espoesedcal caneous bone. The flap chosen was the Cone flap that combine a rotation and a V-Y fasciocutaneousone. Both flap are taken from the sole of the foot and transferred to the ulcer.

Discussion and Conclusion: The treatment of pressure sores of the heel in paraplegic patients is verydifficult because of the low blood supply of this area with a tight and thin skin. The Cone flapisaneasy, reliable and sure one with good results giving blood supply to the area.

\section{Introduction}

Fasciocutaneous flaps have been used frequentely in surgical clinical fields. The distal portion of the leg specially the heels are very difficult area store pair mainly for the friction, shearing and support. When the patient is paraplegic this problema is extreme because they dont have sensitivity. The fasciocutaneous flaps, among others, have been used to solve the pressure sores in the heel because they give good blood supply with good coverage. The fasciocutaneous Coneflap ${ }^{1}$ is a versatile, reliable, reproducible and fast one in order to repair lesions all over the body, also in the heel.
The Cone flap is a combined surgical procedure with a rotation flap and a V-Y advancement flap. The rotation flap covers the defect and the V-Y coversits donor area ${ }^{2-4}$, being both of them, fascio cutaneousones.

\section{Patients and Method}

From 2016 through 2019 we have operated on ten patients with heel pressure sores in the hospital del Salvador, Santiago, Chile.

All patients were men with paraplegia, ageranged from 30 to 65 year sold, with exposed calcaneous bone. The defect was from

\begin{tabular}{|l|l|}
\hline Quick Response Code: & *Corresponding author: Calderon Wilfredo, Plastic Surgery Service, Hospital del Salvador, \\
University of Chile, Santiago, Chile
\end{tabular}


three to six cms in diameter. The prominent calcaneous bon eresected was compromised with osteomielitis. The previous surgical procedure, beforethe Cone flap, was wide debriment and antibiotic suntil getnegative cuantitativet issue cultures.

The rotation fasciocutaneous flap was harvested from the sole of the foot and the fasciocutaneous V-Y advancement lap,that covered the donorarea, was also from the sole of the foot. All the flaps survived completely, despite sutures under tensión, in some patients.

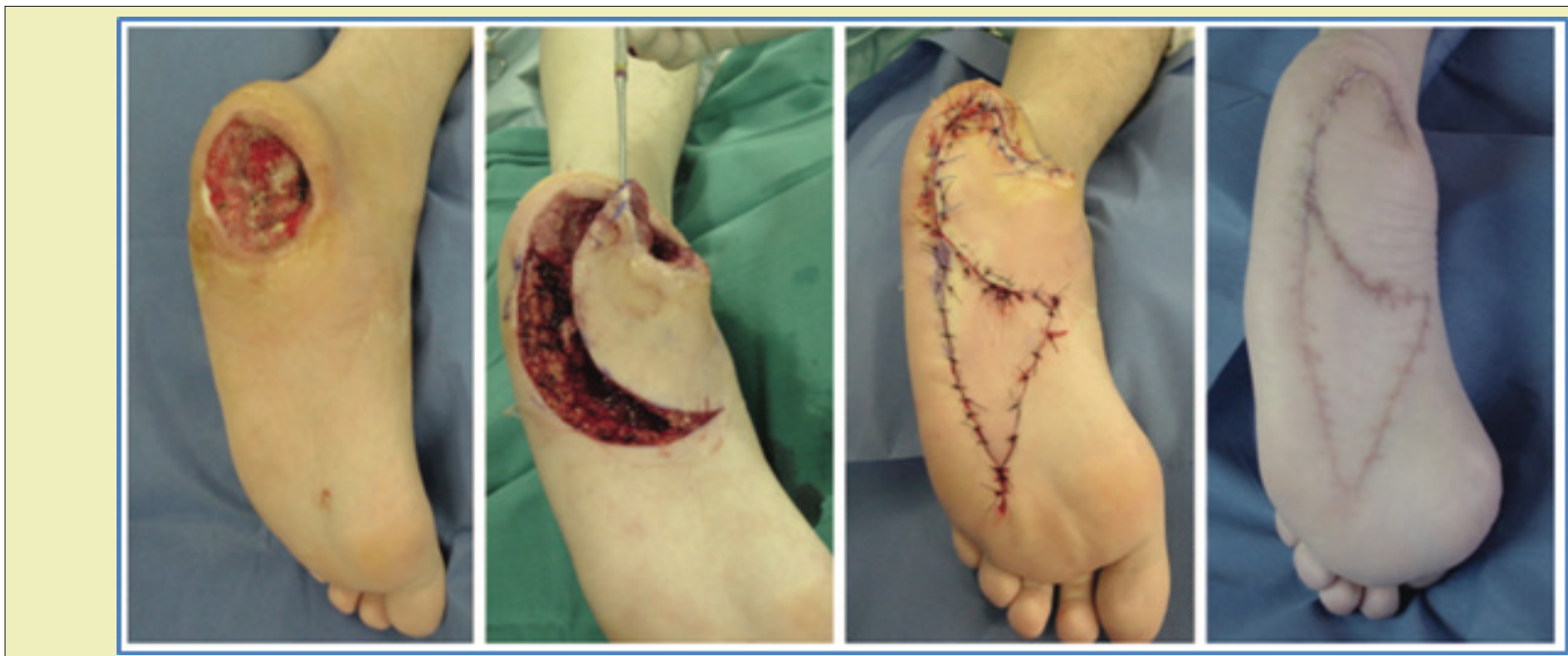

Figure 1: Heel pressure sore fasciocutaneous rotation flap with V-Y advancement flap-cone flap.
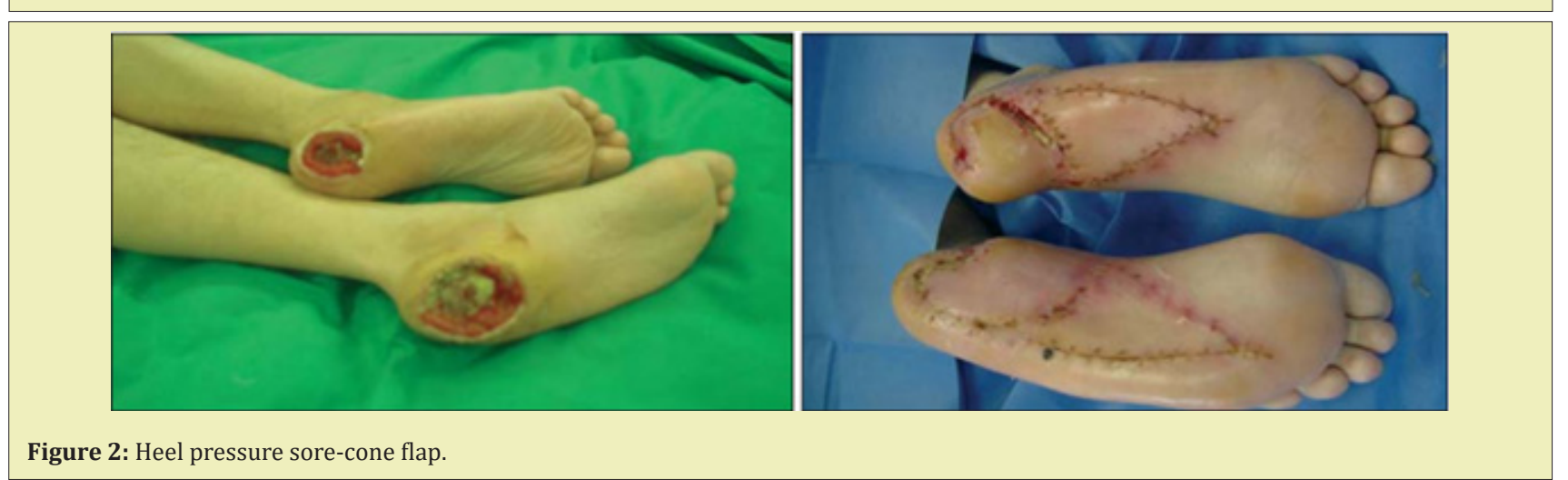

Figure 2: Heel pressure sore-cone flap

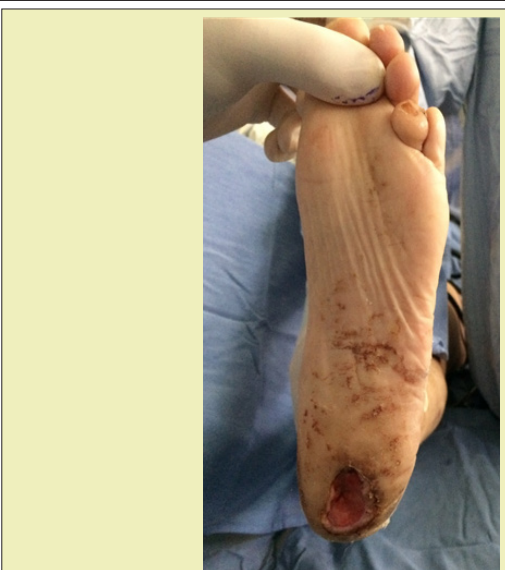

Figure 3(A): Heel pressure sore.
In both flaps the fascia is included in the deep aspect of them. In order to facilitate the advance of the V-Y flap all its perimeter have to be incised through the fascia, so the blood supply is coming from the deep vessels and no from the neighbour tissues. ${ }^{5}$

\section{Results}

All the Cone flaps survived completely. There was no dehiscenceor infection. The follow up was from 6 months toone year (Figures 1-3).

\begin{tabular}{|l|l|} 
Figure 3(A): Heel pressure sore. & Figure 3(B): Fasciocutaneous cone flap. \\
\hline
\end{tabular}




\section{Discussion}

The defect in the heel, secondary to pressure sores in paraplegics patients, is very difficult to treat because is marginally perfused, the skin is thin and tight and frequently associated with osteomielitis. The surgical options for cover age may include muscular, myocutaneous, neurocutaneous fascio cutaneous and free flaps. Fasciocutaneous flaps have demonstrated to be safe, reliable with good blood supply to this area. The donor area, after obtain granulation tissue over the bone, sometimes, have to be covered with Split thikness skin graft but in this kind of patients the friction is a real problem. So the use of the Cone flap allows covering of the defect and the donor are a with strong local flaps is an easy and fast fashion.

\section{Conclusion}

The Cone flap is an easy, reliable and sure one with good results giving blood supply to the pressure sores in the heel in paraplegis patients.

\section{Acknowledgments}

None.

\section{Funding}

None.

\section{Conflicts of Interests}

Author declares that there is no conflict of interest.

\section{References}

1. Calderón W, Andrades P, Cabello R, et al. The cone flap a new and versatile fasciocutaneuos flap. Plas Reconstr Surg. 2004;114(6):1539-1542.

2. Andrades PR, Calderón W, Leniz P, et al. Geometric analysis of the V-Y advancement flap and its clinical applications. Plast Reconstr Surg. 2005;115(6):1582-1590.

3. Calderón WL, Llanos SA, Rodríguez Pena A, et al. Cutaneous island with V-Y closure over a gastrocnemius muscle flap. Plast Reconstr Surg. 2006;118(1):301-302.

4. Calderon W, Rinaldi B, Ortega J, et al. The V-Y advancement for lower eyelid defect in preventing ectropion. Plast Reconstr Surg. 2006;118(2):557-558.

5. Calderón W, Leniz P, Piñeros JL, et al. The fascio-cutaneuos "cone flap" for treatment of electrical burn. Burns. 2007;33(1). 